\title{
Ergonomics and accessibility for people with visual impairment in hotels
}

\author{
Larissa Nascimento dos Santos ${ }^{\mathrm{a},}$ and Ricardo José Matos de Carvalho ${ }^{\mathrm{b}}$ \\ ${ }^{a}$ Post-graduation Programme in Production Engineering, Federal University of Rio Grande do Norte. RN-Brasil \\ ${ }^{\mathrm{b}}$ Production Engineering Department, UFRN, Federal University of Rio Grande do Norte. Natal, RN-Brasil
}

\begin{abstract}
This article presents a diagnosis of luxury or superior hotels in the city of Natal, located in the state of Rio Grande do Norte, in northeastern Brazil, in what concerns accessibility to the visually impaired. The main objective is to present the guiding principles to design actions and interventions that must be considered in the preparation or revision of technical standards and manuals of good practice in accessibility related to people with visual impairments who are hotel users. The survey showed that the hotels do not meet the normative indications of accessibility, their facilities are in-accessible (have prevented access) or of reduced accessibility and its employees are not prepared to provide adequate hospital services for people with visual impairment. It was concluded that some of the accessibility problems faced by people with visual impairments are also faced by people in general.
\end{abstract}

Keywords: ergonomics, accessibility, visual impairment, hotels, tourism

\section{Introduction}

Since 1981, the International Year of Disabled Persons, the interest to adequate the urban environments and public buildings to the needs of people with disabilities has grown. Several national and international laws and norms have emerged, nations, states and municipalities public policies have been drawn and various organizations have introduced this topic, but these initiatives are still shy and predominantly concentrated on motor or physical disabilities. Accessibility for people with visual impairment, the subject of interest in this article, lacks major policies, norms and actions from both the government and business organizations.

Visual impairment is defined as a permanent physical condition which imposes limits to some daily activities of the individual due to decreased visual response. A person is considered a blind if $\mathrm{s} / \mathrm{he}$ suffers from a loss of light perception to the total absence of vision.

According to the census data from IBGE, in 2000, Brazil had 24 million disabled people, being 16.6 million people with some degree of visual impairment, 148 thousand declaring themselves as blind.
From these, 57 thousand are in the Northeast and ${ }^{*}$ $17 \%$ are in the state of Rio Grande do Norte. These data reveal that the population of people with visual impairment has got the potential to arouse the interests of tourism businesses, especially of the hotel branch, and to attract policy formulations and more systematic actions that include it socially in tourism activity and promote its citizenship, quality of life and health.

EMBRATUR points the national hotel industry as the main responsible for the tourism market that, in turn, represents $5.6 \%$ of GDP (gross domestic product) nationwide. Tourism is responsible for the largest share of the economy of Natal, being one of the sectors that most employs and promote the city. Natal has 220 lodging facilities, of which 25 are luxury hotels bearing the rank or luxury (four to five stars). The census of the national hotel quality, realized by the Brazilian Association of the Hotel Industry - AB$\mathrm{IH}$, shows Natal at the eighth position in what concerns the availability of hotels, accounting for $1.2 \%$ of hosting in the national market.

\footnotetext{
- Corresponding authors: larissa.interiores@yahoo com.br
} rijmatos@gmail.com 
Accessibility features, either technological or human, will facilitate the perception of the enviroment that the visually impaired is enjoying, its landscapes and architectural compositions, as well as enable their own mobility and autonomy in this site.

\section{Visual impairment}

Visual impairment can be characterized as blindness, in which visual acuity is equal to or less than 0.05 in the better eye with the best correction option, or as low vision, meaning visual acuity between 0.3 and 0,05 in the better eye with best optical correction. There are even cases in which the sum of the measure of the visual field in both eyes is equal to or less than $60^{\circ}$. (Decree No. 5.296/2004).

It is important to point out that the above mentioned federal decree regulates Law No. 10,048, which gives priority treatment to the people it specifies and requires public direct, indirect and foundational administration bodies, companies providing public services and financial institutions to have trained personnel to attend to people with visual impairments, mental or multiple disabilities, as well as the elderly.

One is considered blind if they have show from a total absence of sight to the loss of light perception. Their learning will be through the integration of the remaining senses preserved and they will have as a primary means of reading and writing the Braille system.

One is considered with low vision if they show from the ability to perceive light to a degree to which visual impairment interferes with or limits their performance. Their learning will be through visual media, even if special features are needed.

Two people with the same accuracy and the same visual field amplitude may show very distinct levels of visual functioning, in a way that, when subjected to different environmental conditions, the same person may show different levels of visual functioning.

Personal (cognitive, sensory, psychological, physical and related to perception) and environmental (color, contrast, time, space and lighting) factors can therefore enhance or increase the level of visual functioning due to changes in visual functions, including in visual acuity, visual field, ocular motility, the brain functions and perception of light and color. (PORTUGAL / Ministry of Education, 2008)

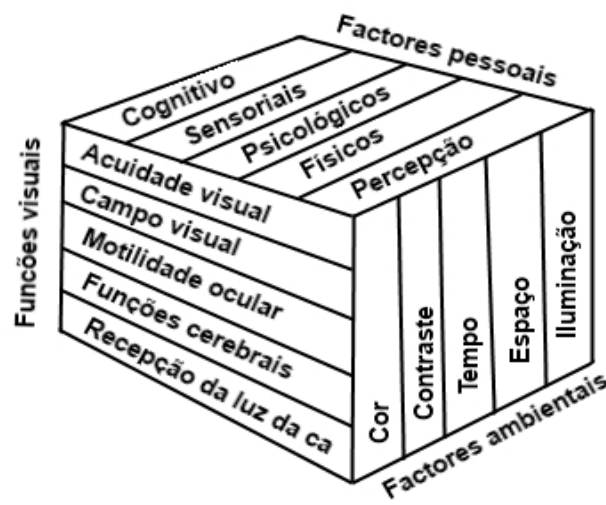

Pic. 1 - Dimensions and components of visual functioning (Translated and adapted from Corn \& Koenig, 1996)

The box of CORN \& KOENING shows the interaction of several factors forming vision capacity. The fact that two people with the same visual acuity have different levels of visual functioning occurs because the visual functioning depends not only on visual functions, but also on the interaction between these and personal and environmental factors.

The pathologies that lead to impaired vision include, mainly, changes in the visual following functions: central vision, peripheral vision and sensitivity to contrasts.

In order to the exchange of messages in providing services to this group to be able, it is necessary to know the public which the care will be directed to and to be sensible to choose the appropriate communication capabilities, without limiting the spread of the message to one kind of communication. There are several types of communication that can be used to achieve this goal. 


\section{Accessibility and hospitality}

Accessibility meets the need of people with disabilities in an environment or the use of equipments, aiming also at the elderly population many restrictions in movement, hearing capacity, eyesight, balance, memory and ability to make decisions in new situations or environment.

According to NBR 9050, the Brazilian technical standard revised in 2004 by ABNT and supported by Federal Law 10098 of 19 December 2000, which deals with the theme Accessibility to Buildings, Furniture, Equipment and Urban Spaces, "to promote accessibility is to give possibility and condition of reaching, perceiving and understanding for people, with safety and autonomy to use the building, space, furniture, equipment and urban elements" (ABNT, 2004).

According to Bins Ely (2004), in order to ensure accessibility, it is necessary to identify the elements that prevent or restrict perception, understanding, movement or appropriation by the users of the spaces and activities, as well as social and psychological barriers to an effective use. The barriers of accessibility can be divided into three categories (Bins Ely, and Dischinger Mattos, 2002):

a) Socio-Cultural Barriers: also known as attitudinal barriers, they are present in the context of social relations, ie, on the image focused exclusively on the deficiencies of individuals with some physical, sensory or mental limitation, and not on their capabilities. This prejudiced view constitutes a strong barrier to social inclusion.

b) Physical Barriers: these are the obstacles of architectural origin, or related to the design of equipment and products that hinder or completely prevent the independent access of a user.The identification of physical barriers requires a very careful study of the universe of users who make use of the environment.

c) Information Barriers: elements of environmental information (architectural, the object or additional) that disrupt or reduce the possibilities of obtaining the desired spatial information. These barriers greatly influence the accessibility, since they are directly linked to an individual's ability to orient and move in an environment.

Hospitality "is a privileged way of interpersonal meeting marked by the welcoming attitude toward the other" (Baptista, 2002, p.157). Thus, hospitality "includes the relationship established between the physical space of the city and its inhabitants (...) providing a sense of well-being" (GRI-Nover, 2002, p. 26).

Tourism industry depends essentially on the quality of service rendered during the stay of tourists and hence the products and services developed to promote the comfort and satisfaction of tourists are explicit forms of hospitality. To the person with disabilities, hospitality is hampered by the lack of accessibility, a factor that excludes this portion of society from effective participation in tourism activity.

Hospitality is a key factor for implementation of the adaptation of tourism services, considering that to be done in an adequate way it is also necessary that there be training of the staff involved in providing the service (SOUZA, 2010).

According to Dencker (2004), when recognizing that the problem of exclusion and the breakdown of solidarity are factors affecting hospitality, we have to turn such limits into a challenge, asking about our responsibility as the source of the problem and acting effectively to overcome it.

Recognition of the need to make hotel ventures accessible and the development of specific products for this demand of guests is an important aspect in hospitality management, considering that guests with disabilities have the same right to exercise their citizenship and be included in the same environment as the rest of society.

Hospitality, tourism and inclusion are concepts that should guide a work that aims to change the paradigm, considering that hospitality can be understood as a means of creating and consolidating relationships; tourism, one of the activities by which relationships are strengthened; and inclusion, a guiding goal of this involvement (MENDES \& PAULA, 2008, p. 335).

Tourism uses hotel spaces to effectively happen, and for being the place where tourists seek to best enjoy their time to rest, the design of such environments or of technologies at these sites should provide a warm and accessible environment to all population segments that may stay, including the visually impaired.

\section{Ergonomics}

In August 2000, the IEA - International Ergonomics Association defined Ergonomics (or human factors as the association also considers it) by: 
A scientific discipline related to the understanding of the interactions between humans and other elements or systems, and to the application of theories, principles, data and methods to design in order to optimise human well being and overall system performance. Ergonomists contribute to the planning, design and evaluation of tasks, jobs, products, environments and systems to make them compatible with the needs, skills and limitations of people (IEA, 2000).

The role of the ergonomist in what concerns technical aids for people with special needs on the one hand is relatively classic: contribution in the conception of new aids, evaluation of prototypes in different stages of the design process, analysis of the needs of people with special needs in business and private fields, at home and in public spaces, advice on the choice of more appropriate systems considering the characteristics of each particular case. It is this latter role of the ergonomist - the choice of systems which best suit each particular case - which seems to differentiate most from the habitual ergonomic action (Uzan \& Sperandio, in Falzon, 2007).

The ergonomic action is characterized as a dynamic consultation that goes gradually from the definitions initially outlined by the organization to building a precise object of intervention, defined foci of its action and adjusted modalities of action (Vidal, 2008). The ergonomic action must meet and satisfy a greater number of people and exclude the less possible; it must be prepared to analise all activities and solve problems faced by the people who run it. It mus also attend to people who have special needs, seeking to adapt the spaces experienced by these people.

Thanks to ergonomic studies it can be said that equipment that meet the average user do not fulfill its function of inclusion, because there is no doubt they fail to meet comfortably half of the people. The universal approach implies meet the extreme, considering the activities that will be developed, which sometimes leads to the adoption of several similar devices (BURJATO, 2004, apud BURJATO \& LOPES, 2010).

\section{Methodology}

The sample of the accessibility mapping consists initially of all hotels in Natal that are ranked with four to five stars, for a total of 17 , according to the classification of the Brazilian Hotel Industry of Rio Grande do Norte, which follows the requirements of the Manual for the Evaluation of Lodging Media of the Brazilian Hotel Industry Association - ABIH.

It was used a qualitative and quantitative research methodology, being it descriptive, analytical and interpretative. Preliminarily, it was realised a bibliographic research, seeking to constitute the theoretical framework, the conceptual basis and the state of the art of the theme. Ergonomic Work Analysis was taken as a basis for field studies, beginning with a study of the demands of accessibility of hotels, by applying interactional (interviews and conversational actions with managers and staff) and observational techniques (in loco observation of the built environment of the hotels).

A protocol was developed and applied to evaluate the compliance of accessibility of hotels in face of the Brazilian technical standard NBR 9050 (2004). Interviews were conducted with blind and low vision people in three state capitals of the country - Natal, João Pessoa, Rio de Janeiro - in order to know accessibility difficulties they faced in hotels and the improvement recommendations they indicated.

A blind person was accompanied during a day in a luxury hotel in the cities of Rio de Janeiro and Natal to observe and record the activities performed by them at the hotel and the difficulties of accessibility. On this occasion, there were observations, structured interviews and conversations with that person with respect to the accessibility related to anything in their experience at the hotel.

The actions of field research were documented through photographic and audio-visual records, from which the analysis was performed.

\section{Results}

To assess the physical condition of the hotels in terms of accessibility to the visually impaired, it was used the "Checklist - accessibility to the visually impaired". The list was created in accordance with NBR 9050 (ABNT, 2004), where there were addressed aspects refering to accessibility to the visually impaired. Considerations raised by the visually impaired during conversational actions were also added to the list.

We divided the hotel environments and external area in seven (07) groups to be analyzed through the list: reception, bedroom, pavement/access, internal circulation, vertical circulation (stairs, elevators, ramps), WCs and general. With this instrument we confirmed that the hotels are not designed consider- 
ing the norms of accessibility for people with visual impairments.

According to Chart 1, 17 researched hotels differentiate greatly in the positive aspects found in the housing units (apartments), there being a variation in the percentage of satisfaction in accordance with the items surveyed from 0 to $71 \%$. Some features that are considered highly important to ensure autonomy to the visually impaired, as Braille signs on doors indicating the apartment number and tactile floors that lead guests with visual impairments to the room, were not found in any of the hotels in the sample. This relevance was related by the people with visual impairment in interviews. Only $24 \%$ of the hotels have got a transcription to Braille of the directory of services offered. This feature prevents the guest to connect to the front desk to ask about schedules and rules, for example. where the handle is at a height between $0.90 \mathrm{~m}$ and $1.10 \mathrm{~m}$. Hotels customize signaling according to the theme of its setting, and because of this, only $12 \%$ of them have visual signaling in contrasting colors and size appropriate for people with low vision. This type of signaling is interesting; it is not recommended by the standard, but can be done provided it is correctly added to complement the customised information. Picture 1 shows how the visual and tactile signs of an apartment should be in a hotel, maintaining customised characteristics: number in large font and color contrast between text and background and tactile information added to the doorway, beside the handle, allowing the visually impaired to get information to find the room.

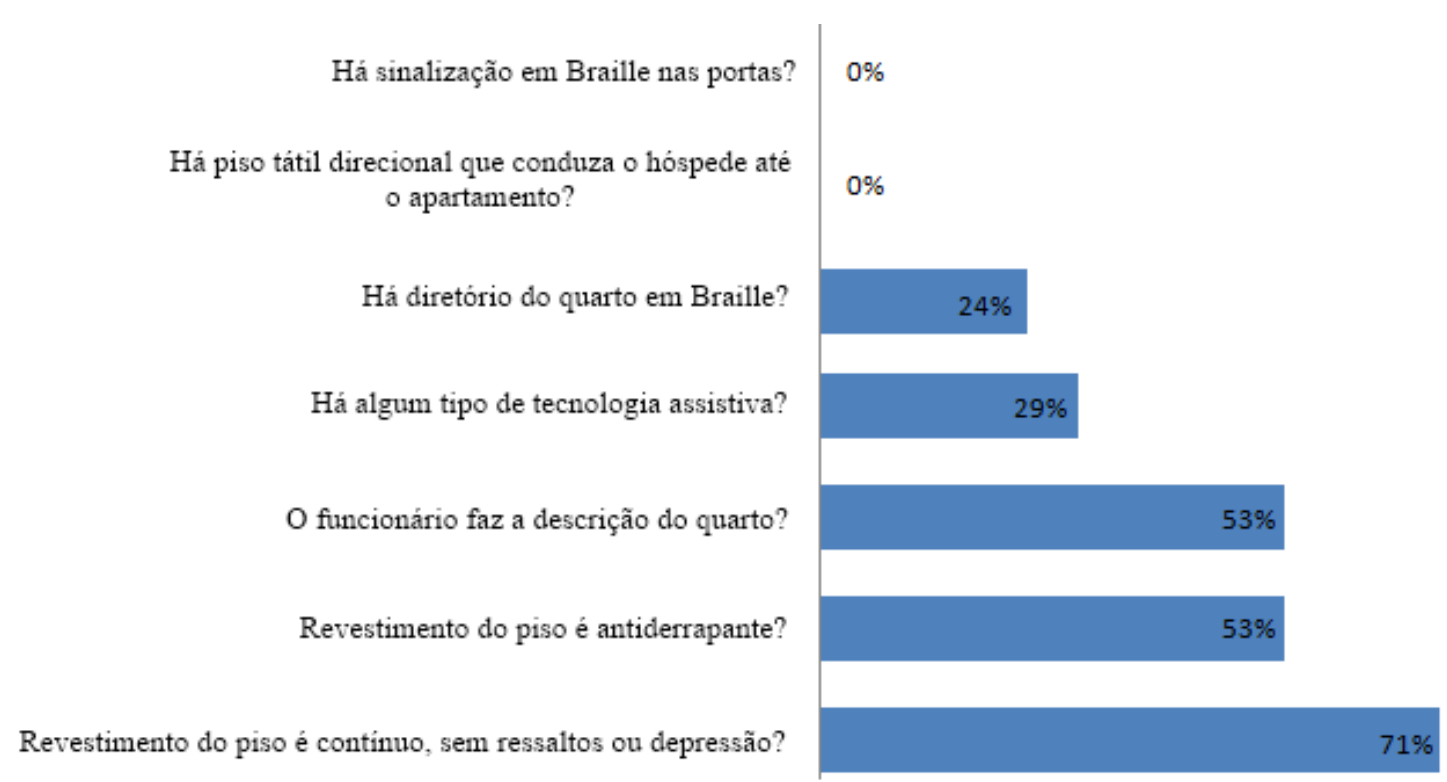

Chart 1 - Level of compliance of hotels in the city of Natal-RN to the items discussed in the dorms. Source: Project ERGOPOLIS - grep / PEP / UFRN

Chart 1 also shows that in $53 \%$ of the hotels the staff make the room description to the guest with visual impairment, but these data are insufficient since most of the times these employees are not trained for this function, making the description in an informal way and often not meeting the understanding of the guest.

According to NBR 9050/2004, for the identification of doors, tactile signs (in Braille or with text on them) must be installed in adjacent stops or even on walls, partitions or panels on the side 


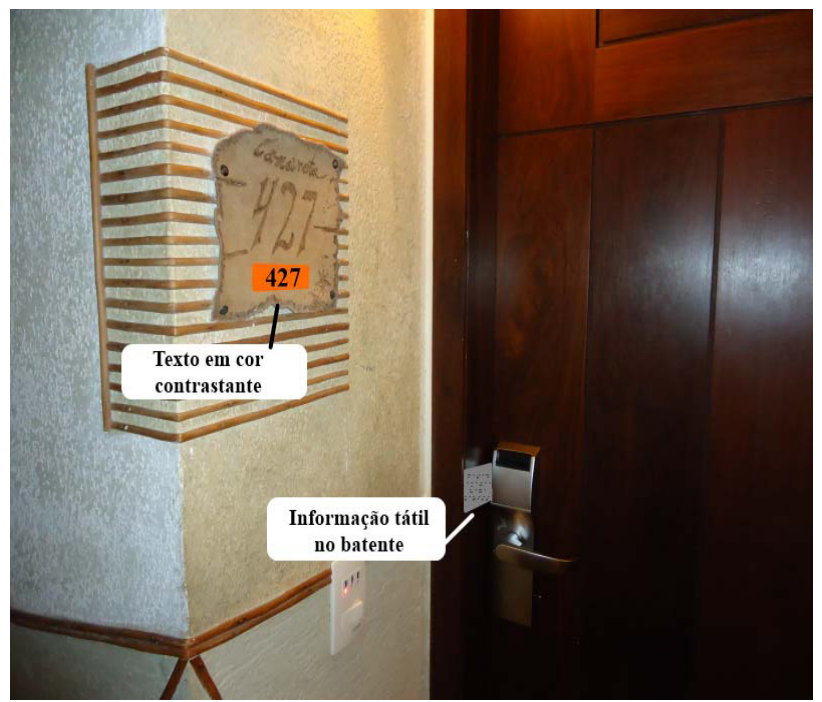

Pic. 2 - Proposed signage on the door of an apartment

Another aspect that is not covered by the standard, but that was seen as inaccessible to people with visual impairment is the card used as the key of the apartment. It was observerd that the guest has got difficulty in finding the correct side to position the card and release the lock. This happens even with people who see normally, because they do not find an information which is easy to interpret. We recommend that the information in Braille and an arrow in relief, where it would be written: "This side forward and upward" was inserted on the card. This same text in ink would make things easy both to people who can see well and people with low vision.

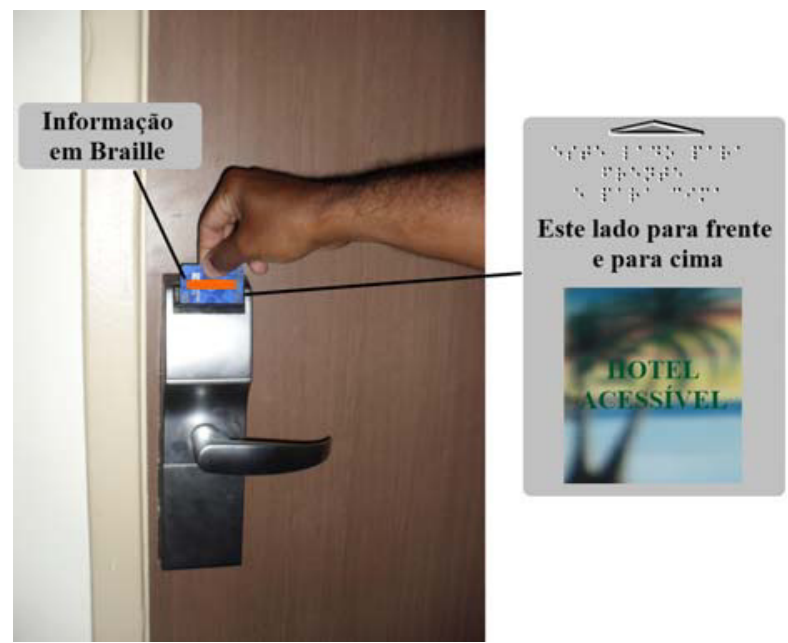

Pic. 3- Proposal of the opening card with Braille
Only $24 \%$ - ie, 4 out of 17 - of the hotels offer a restaurant menu in Braille. The menu in Braille ensures greater autonomy to a blind person (who has mastery in reading this language) when choosing a dish or deciding where to have a meal when considering prices. In addition, the feature facilitates the understanding of the information and preserves the privacy of consumers at the moment of choice, since they do not need the help of others to read the menu.

As for overhead obstacles, such as marquees, signs, fire extinguishers on walls, awnings and vegetation, only $29 \%$ of the researched hotels keep them at a height greater than $2.10 \mathrm{~m}$. But none of the hotels has warning tactile floor under this furniture, putting guests with visual impairments to an accident-risky situation. Picture 3 shows the proposed tactile signal warning to the presence of fire extinguishers, where, according to NBR 905/2004, the surface to be marked must exceed in $0.60 \mathrm{~m}$ the projection of the obstacle, on the whole surface or only in its perimeter.

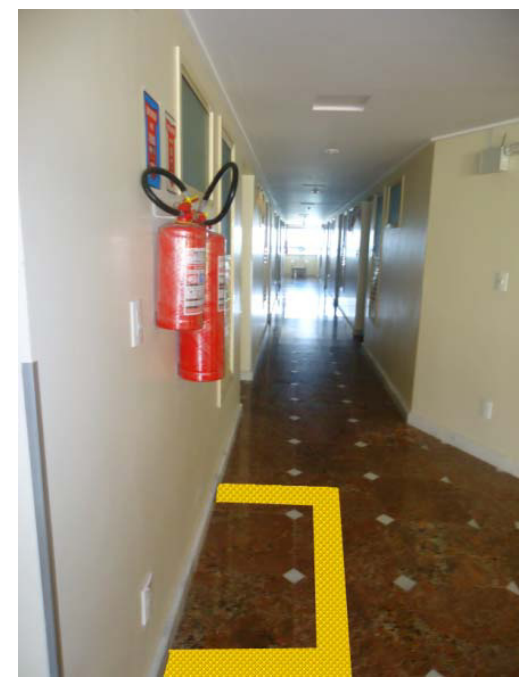

Pic. 4 - Proposal for tactile signaling and warning signs below fire extinguishers

Some general conditions have been synthesized to raise the global situation of the hotel enterprises of Natal. As for accessibility in the path that connects the building to the street, the other outbuildings of common use of guests and neighboring buildings, $41 \%$ of the hotels meet this requirement. The others do not have an accessible surrounding, especially those in Ponta Negra beach which are often located on steep streets with of sidewalks in a bad state. 
Guests need to reach the interior of the establishment without difficulty, because an accident on the entrance represents unsafety in the whole stay. We consider that $65 \%$ of the researched hotels have at least one of the accesses to the interior of the building free of architectural barriers and obstacles that prevent or hinder its accessibility (Chart 2).
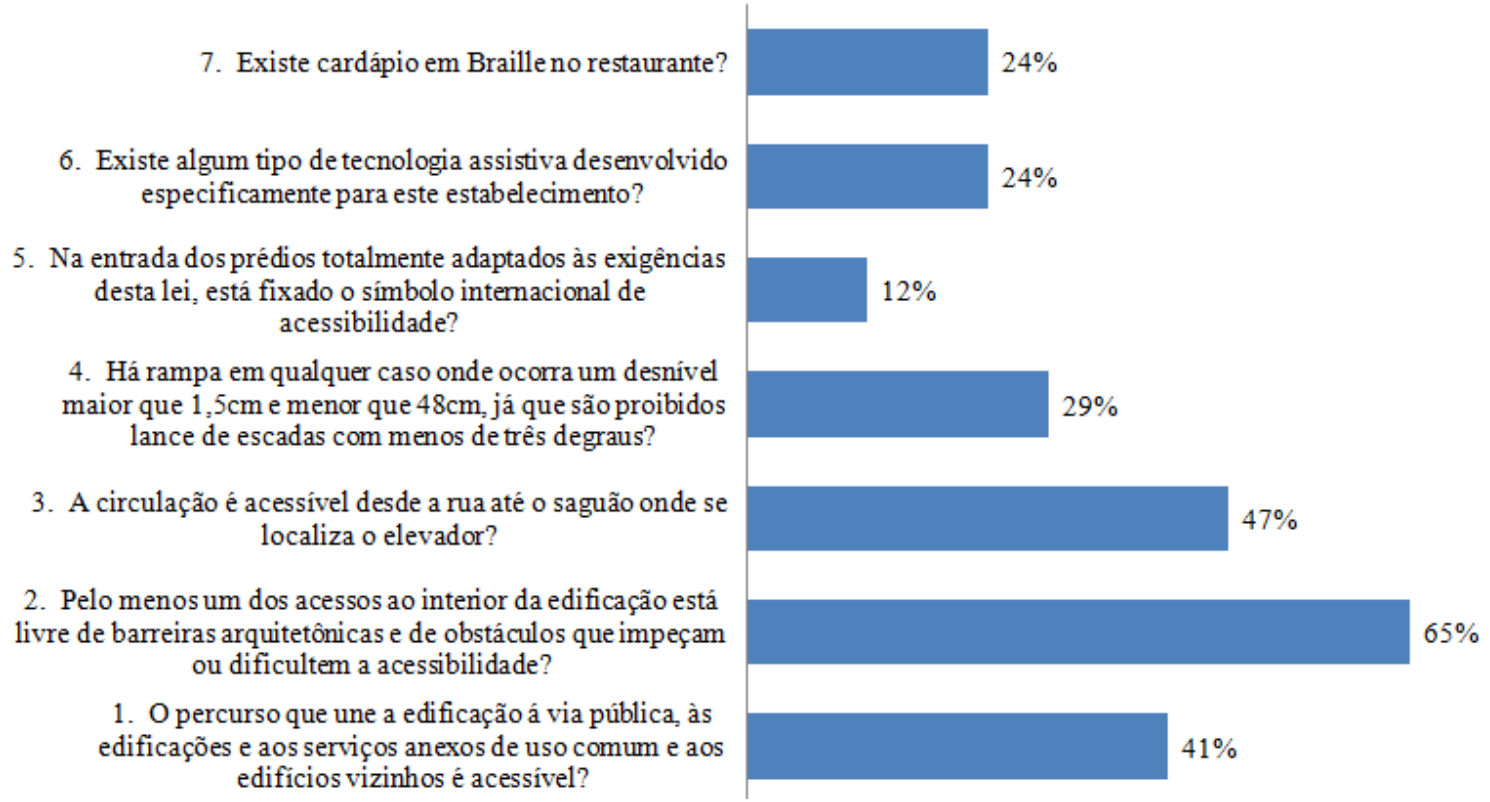

Chart 2 - Compliance of the researched hotels with the general aspects of accessibility

The hotels still have management problems due to both the human part of their employees and to the physical part of its structure. Serious mistakes caused by lack of knowledge of the management team in adapting their enterprise or even as a way to take advantage of some asset in their favour greatly hinder the stay of a guest who has got any disability. Picture 4 shows the negligence involved at the time of installation of the elevator button panel, where, besides symbols of which the dimensions are smaller than 16 $\mathrm{mm}$, making it difficult to be used by a person with low vision, the Braille indication is used incorrectly. It is written "up" in Braille on the board (upside down); it should be used to indicate this sense if positioned correctly with the black arrow up, but the button panel was installed with the down arrow indicating to the people who can see it that the lift will descend, thus impairing Braille reading for the visually impaired. Problems like this show the little importance that managers give to making life easier for people with visual impairments.

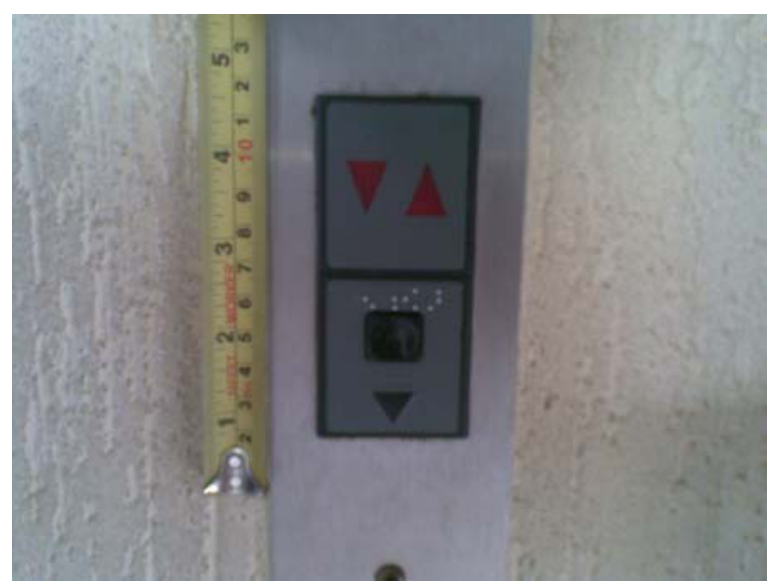

Pic. 5 - Button panel of the elevator installed upside down, jeopardizing the Braille reading. Source: Collection of photographic project ERGOPOLIS/GREPE/UFRN 


\section{Conclusion}

Observations made, reports and descriptions of the perception of people involved in the interactions made possible, on the one hand, to understand the level of accessibility of hotels and understand their current and future actions in this direction and, on the other hand, to characterize the spatial orientation of a visually impaired person in an environment, emphasizing the interdependence of the individual interactions with the situational space.

It was observed that the hotels do not meet the normative indications of accessibility, because their environments are inaccessible, offer risks to the user's safety, do not guarantee the proper independence or adequate comfort to their stay. In addition, employees find themselves unprepared to provide adequate hospital services for people with visual impairment.

It was concluded that some of the accessibility problems faced by people with visual impairment are also faced by people in general. We found that few hotels meet the requirements considered of high relevance for a comfortable and independent stay of a guest with a visual impairment, such as directional tactile floor that leads guests with visual impairment to the room and other common use environments and directory of services of the hotel in Braille. Most adaptations for the visually impaired in hotels is considered simple and yet much remains to be done for this demand. Practices as how to use signage in contrasting colors and letters in large fonts help people with low vision. Inserting floors (or guides) and tactile maps to improve mobility through environments, transcribing hotel menus and directories to Braille and providing tactile information on the doors and elevators is an easy and simple to enable initiative. Moreover, it is essential that there be training to enable employees to attend to these people correctly, respecting its limitations and understanding their unique characteristics.
There is a need to continue and generate further discussion about the consideration of ergonomics in the design that will attend to these people, spreading the concept of accessibility and hospitality to people with disability in hotels, looking at the specifics of each type of disability.

\section{References}

[1] EMBRATUR. Manual de Recepção e acessibilidade de pessoas portadoras de deficiência a empreendimentos e equipamentos turísticos. Disponível em: www.embratur.org.br. Acesso 14/04/2010.

[2] PORTUGAL. Ministério da Educação. Alunos cegos e com baixa visão: orientações curriculares. 2008. 88p.

[3] BRASIL. Decreto $\mathrm{n}^{\circ} 5.296$ de 2 de Dezembro de 2004. Regulamenta as Leis $\mathrm{n}^{\mathrm{o}} \mathrm{s} 10.048$, de 8 de novembro de 2000, e 10.098 , de 19 de dezembro de 2000

[4] ASSOCIAÇÃO BRASILEIRA DE NORMAS TÉCNICAS. NBR 9050, Acessibilidade a Edificações, Mobiliário, Espaços e Equipamentos Urbanos. Rio de Janeiro, 2004. 59p.

[5] Corn, A.L., Koenig, A.J. Foundation of low vision: Clinical and functional perspectives. New York: AFB Press. 1996.

[6] Grinover, Lucio. Hospitalidade: um tema a ser reestudado e pesquisado. IN: DIAS, Célia Maria Moraes. Hospitalidade: Reflexões e Perspectivas. São Paulo: Manole, 2002.

[7] Souza, C., C. Acessibilidade Para Deficientes Visuais Em Hotéis: O Caso Do Sesc Copacabana. In: Jornadas de Turismo Acessível. Odivelas, 2010.

[8] Bins, E., V. H. M. Acessibilidade Espacial - Condições Necessárias para o Projeto de Ambientes Inclusivos. In: Moraes, Anamaria (Org.). Ergodesign do Ambiente Construído e Habitado: Ambiente Urbano, Ambiente Público, Ambiente Laboral. Rio de Janeiro: iUsEr, 2004

[9] Mendes, Bruna C.; Paula, Nilma Morcerf de. A Hospitalidade, o Turismo e a Inclusão Social para Cadeirantes. Turismo em Análise, v. 19, n. 2, p.329-342, ago. 2008.

[10] Sperandio, J., Uzan, G. Ergonomia dos suportes técnicos informáticos para pessoas com necessidades especiais. In: Falzon, Pierre. Ergonomia. São Paulo: Editora Blucher, 2007.

[11] Vidal, M. C. Guia para Análise Ergonômica do Trabalho na empresa: uma metodologia realista, ordenada e sistemática. Rio de Janeiro $2^{\mathrm{a}}$ ed. Virtual Científica. 2008. 